\title{
EXIGÊNCIA DE LISINA PARA CODORNAS JAPONESAS (Coturnix japonica) NA FASE DE CRIA ${ }^{1}$
}

\author{
Lysine requirement for growing japanese quails (Coturnix japonica)
}

\author{
Adolpho Marlon Antoniol de Moura 2 , Rita da Trindade Ribeiro Nobre Soares, \\ José Brandão Fonseca ${ }^{4}$, Ricardo Augusto Mendonça Vieira ${ }^{3}$, Humberto Pena Couto ${ }^{3}$
}

\begin{abstract}
RESUMO
Foram utilizadas 400 codornas fêmeas com peso médio de 7,3g $\pm 0,3 \mathrm{~g}$ no período de um a 42 dias de idade. O delineamento experimental foi o inteiramente casualizado, com cinco tratamentos e quatro repetições com 20 aves por unidade experimental. Os tratamentos consistiram em cinco níveis de lisina total na ração $(0,90 \% ; 1,05 \% ; 1,20 \% ; 1,35 \% ; 1,50 \%)$. As características avaliadas foram: consumo de ração médio diário (g/ave/dia) e acumulado (g/ave/período); peso médio das aves (g), ganho em massa corporal acumulado (g/ave/período), conversão alimentar (g de ração consumida/g de ganho de peso), mortalidade (\%/período) e uniformidade (\%/período). Também foi descrita a curva de crescimento das codornas para cada nível de lisina total utilizado. Não foi verificado efeito significativo para nenhuma das características avaliadas ( $\mathrm{P}>0,05)$. O nível de $0,90 \%$ de lisina total em rações com 20,70\% de proteína bruta atendeu às exigências de codornas japonesas durante o período de crescimento, correspondendo a um consumo diário, por ave, de $96,9 \mathrm{mg}$ de lisina total.
\end{abstract}

Termos para indexação: Codorna japonesa, curva de crescimento, exigência nutricional, lisina.

\begin{abstract}
In a study to establish total lysine requirement for growing japanese quails, 400 female quails $7.3 \mathrm{~g} \pm 0.3 \mathrm{~g}$ mean body weight were used from one to 42 days of age. A completely randomized experimental design was adopted, with five treatments and four replicates, with 20 birds per experimental unit. The treatments were five total lysine levels in the diet $(0.90 \% ; 1.05 \% ; 1.20 \% ; 1.35 \%$ and $1.50 \%)$. The evaluated data were: daily feed intake ( $\mathrm{g} / \mathrm{bird} /$ day); total feed intake (g/ bird/ period); body weight ( $\mathrm{g} / \mathrm{bird})$; total body weight gain (g/ bird/ period); feed conversion rate ( $\mathrm{g}$ of feed intake / $\mathrm{g}$ of weight gain); mortality (\% / period) and uniformity (\% / period). The growing curve of the quails fed each total lysine level studied was also described. There was no statistical significant effect for all the evaluated data $(\mathrm{P}>0.05)$. The level of $0.90 \%$ total lysine in $20.70 \%$ crude protein diet met the requirement of japanese quails during growing period, equivalent to a daily total lysine intake of $96.9 \mathrm{mg} / \mathrm{bird}$.
\end{abstract}

Index terms: Growing curve, japanese quail, lysine, nutritional requirement.

(Recebido em 31 de janeiro de 2006 e aprovado em 5 de outubro de 2006)

\section{INTRODUÇÃO}

A coturnicultura se destaca, atualmente, como uma das principais atividades avícolas no cenário do agronegócio brasileiro. O franco desenvolvimento da atividade é reforçado pela maior participação de grandes empresas avícolas, que aperfeiçoam as técnicas de manejo e investem em modernas instalações, o que possibilita alojar um número cada vez maior de aves em um mesmo galpão (BERTECHINI et al., 2002). Além disso, o melhoramento genético e a nutrição animal, caminham na busca por linhagens mais produtivas e formulações mais adequadas às exigências nutricionais das codornas japonesas.

Os avanços da nutrição animal, particularmente em função de uma maior compreensão do metabolismo protéico e de novas tecnologias para a produção de aminoácidos sintéticos, em escala industrial, possibilitam o refinamento das técnicas de balanceamento e otimização de dietas. com o intuito de atender às exigências nutricionais em, proteínas, aminoácidos e energia, bem como minimizar as perdas em nutrientes e a poluição ambiental pelos sistemas de produção avícola (BAKER \& HAN, 1994; KLASING, 1998).

Neste sentido, o uso de aminoácidos sintéticos possibilita o atendimento às exigências em aminoácidos limitantes e a concomitante redução do teor de proteína bruta da ração. Para tanto, ajustes na matriz nutricional dos ingredientes disponíveis e nas exigências nutricionais para cada fase produtiva das aves devem ser efetuados (SUIDA, 2001).

\footnotetext{
${ }^{1}$ Parte da dissertação de mestrado apresentada, pelo primeiro autor, ao Programa de Pós-graduação em Produção Animal CCTA/UENF.

'Zootecnista, Doutorando em Produção Animal - Laboratório de Zootecnia e Nutrição Animal/LZNA - Universidade Estadual do Norte Fluminense Darcy Ribeiro/UENF - Avenida Alberto Lamego, 2000, Horto - Campos dos Goytacazes, RJ - 28013-600 - antoniol@uenf.br - Bolsista, CAPES. ${ }^{3}$ Professor Associado - Laboratório de Zootecnia e Nutrição Animal/LZNA - Universidade Estadual do Norte Fluminense Darcy Ribeiro/UENF _ Avenida Alberto Lamego, 2000, Horto - Campos dos Goytacazes, RJ - 28013-600 - rnobre@uenf.br; ramviera@uenf.br ; hpcouto@uenf.br ${ }^{4}$ Professor Titular - Laboratório de Zootecnia e Nutrição Animal/LZNA - Universidade Estadual do Norte Fluminense Darcy Ribeiro/UENF - Avenida Alberto Lamego, 2000, Horto - Campos dos Goytacazes, RJ - 28013-600 - jfonseca@uenf.br
} 
A lisina (Ácido 2,6 diamino-hexanóico) é considerada aminoácido essencial porque é sintetizada nos tecidos em quantidade insuficiente para atender às necessidades das aves, o que obriga ao uso de lisina préformada, presente na proteína intacta alimentar ou em fontes sintéticas como a L-lisina - HCl (KLASING, 1998).

As principais funções da lisina para aves em crescimento relacionam-se à formação dos tecidos ósseo, muscular e na síntese de carnitina. A lisina exerce função específica na síntese de proteína muscular em frangos de corte. Todavia, há a necessidade de verificar se tal asserção é válida para codornas, pelo menos, em termos de maior resposta em crescimento corporal (NASCIMENTO, 2003).

A disponibilidade de lisina na forma pura, no mercado, a um custo economicamente viável, pode viabilizar o seu uso na suplementação de rações com baixo teor de proteína bruta. A lisina sintética possui atividade de 78,4\%, em relação à lisina natural, e coeficiente de digestibilidade de $100 \%$.

O amadurecimento precoce das codornas ( 35 a 42 dias de idade) induz à necessidade de programas alimentares que maximizem a taxa de crescimento e o bom desenvolvimento corporal, o que as permite atingir o peso ideal à maturidade sexual e assegurar maior uniformidade do plantel durante a postura (PINTO, 2002).

Um dos pontos de estrangulamento da atividade é a insipiência de dados concretos sobre as exigências nutricionais de codornas, em particular às exigências aminoacídicas. No intuito de fornecer subsídios para formulações mais adequadas foi conduzido um experimento para avaliar o desempenho de codornas japonesas alimentadas com diferentes níveis de lisina durante a fase de crescimento.

\section{MATERIAL E MÉTODOS}

O experimento teve duração de 42 dias e foi conduzido no setor de avicultura (LZNA/CCTA) da Universidade Estadual do Norte Fluminense Darcy Ribeiro, localizado em Campos dos Goytacazes, RJ, Brasil. Foram utilizadas 400 fêmeas de codornas japonesas (Coturnix japonica), com um dia de vida e peso médio de $7,3 \pm 0,3 \mathrm{~g}$.

As aves foram distribuídas em 20 boxes de 1,5 x $2,0 \mathrm{~m}$, cercados com telas de plástico de abertura $0,5 "$, alocados em galpão de alvenaria, e telhas de barro. Foi utilizado o delineamento inteiramente casualizado composto por cinco tratamentos (níveis de lisina), quatro repetições e vinte aves por unidade experimental (box). O critério para distribuir as aves dentro dos boxes foi o peso médio.

Em cada box foram colocadas 20 codornas em círculo de proteção onde permaneceram até completarem 35 dias, sob campânula com lâmpada de 100 watts, com a altura regulada de acordo com o comportamento das aves frente às condições ambientais, conforme recomendado por Murakami \& Ariki (1998). Foi disponibilizado, por box, um bebedouro (copo de pressão) e um comedouro (tipo prato) colocados sobre bandejas de aço para recolhimento das sobras de ração. Foi utilizada sobre o piso, como cama, a casca de arroz. As rações experimentais foram acondicionadas em baldes plásticos, com tampa, devidamente identificados e fornecidas à vontade, assim como a água.

As condições ambientais a que foram expostos os animais foram registradas, três vezes ao dia, por meio dos seguintes instrumentos: termômetros de máxima e de mínima, de bulbo seco, bulbo úmido e de globo negro, dispostos à meia altura do corpo dos animais. Esses dados foram utilizados para calcular o índice de temperatura de globo e umidade (ITGU), proposto por Buffington et al. (1981).

Foram testados cinco níveis de lisina total, sendo uma ração basal (Tabela 1) deficiente em lisina e complementada com lisina sintética (L-lisina-HCl), em substituição ao amido, para se obterem os níveis desejados, a saber: $0,90 \% ; 1,05 \% ; 1,20 \% ; 1,35 \%$; e 1,50\%. As rações experimentais foram formuladas com milho, farelo de soja e glúten de milho e suplementos minerais e vitamínicos, seguindo as exigências nutricionais para codornas japonesas em crescimento constantes no NRC (1994), com exceção da proteína bruta e da lisina total.

Os insumos e as rações experimentais foram analisados, no Laboratório de Zootecnia e Nutrição Animal (CCTA/UENF), para determinação dos teores de matéria seca (MS), proteína bruta (PB), extrato etéreo (EE), cálcio (Ca) e fósforo total (P), segundo as metodologias descritas por Silva (1990). Os percentuais dos aminoácidos lisina, metionina+cistina, treonina e triptofano e de fósforo disponível foram corrigidos, a fim de garantir a composição nutricional desejada.

As variáveis avaliadas ao término do período experimental foram: consumo de ração médio diário ( $\mathrm{g} /$ ave/dia) e acumulado (g/ave/período), peso médio das aves (g), ganho em massa corporal acumulado (g/ave/ período), conversão alimentar (g de ração consumida/g de ganho de peso), mortalidade (\%/período) e uniformidade (\%/período). 
TABELA 1 - Composição percentual e calculada da ração basal experimental para codornas em crescimento.

\begin{tabular}{|c|c|}
\hline \multicolumn{2}{|c|}{ Composição Alimentar } \\
\hline Ingredientes & Quantidade (\%) \\
\hline Milho moído $(7,12 \% \text { PB })^{2}$ & 59,937 \\
\hline Farelo de Soja $(45,24 \% \text { PB })^{2}$ & 23,831 \\
\hline Farelo de Glúten de Milho $(60,03)^{2}$ & 9,018 \\
\hline Óleo de Soja & 3,000 \\
\hline Calcário Calcítico & 1,123 \\
\hline Fosfato Bicálcico & 1,053 \\
\hline Amido de Milho & 1,000 \\
\hline Suplemento Vitamínico e Mineral ${ }^{1}$ & 0,500 \\
\hline Sal comum $(\mathrm{NaCl})$ & 0,276 \\
\hline L-Lisina.HCl $(78,4 \%)$ & 0,000 \\
\hline DL-Metionina (99\%) & 0,020 \\
\hline L-Treonina (99\%) & 0,244 \\
\hline
\end{tabular}

\section{Composição Nutricional Calculada}

\begin{tabular}{lc}
\hline${\text { Proteína Bruta }(\%)^{2}}^{2}$ & 20,700 \\
Energia Metabolizável (Kcal/kg) $^{3}$ & 2.900 \\
Fibra Bruta (\%) & 2,600 \\
Cálcio (\%) & 0,800 \\
Fósforo disponível (\%) & 0,300 \\
Lisina (\%) & 0,900 \\
Metionina + Cistina (\%) & 0,750 \\
Treonina (\%) & 1,000 \\
Triptofano (\%) & 0,215 \\
Sódio (\%) & 0,150 \\
\hline
\end{tabular}

${ }^{1}$ - Composição/kg do produto: Vit.A, 2.500.000 UI; Vit. $\mathrm{D}_{3}$ 625.000 UI; Vit. E, $3.750 \mathrm{mg}$; Vit. $\mathrm{K}_{3}$, 500mg ; Vit. $\mathrm{B}_{1}, 500 \mathrm{mg}$; Vit. $B_{2}, 1.000 \mathrm{mg}$; Vit. $B_{6}, 1000 \mathrm{mg}$; Vit $B_{1}, 3.750 \mathrm{mcg}$; Niacina, $7.500 \mathrm{mg}$; Ácido pantotênico, $4.000 \mathrm{mg}$; Biotina, $15 \mathrm{mg}$; Ácido fólico, $125 \mathrm{mg}$; Colina, $75.000 \mathrm{mg}$; Selênio, $45 \mathrm{mg}$; Iodo, 175 mg; Ferro, 12.525 mg; Cobre, 2.500 mg; Manganês, 19.500 mg; Zinco, $13.750 \mathrm{mg}$; B.H.T., $500 \mathrm{mg}$; Vit. C, $12.500 \mathrm{mg} .{ }^{2}$ Analisado no Laboratório de Zootecnia e Nutrição Animal (CCTA/UENF) ; ${ }^{3-}$ Calculado segundo Rostagno et al. (2000).

A partir das estimativas regulares de peso tomadas nas diferentes unidades experimentais, foi estimado o padrão de crescimento animal segundo o modelo de Gompertz (1825), descrito por Zwietering et al. (1990):

$$
Y_{i}=a \cdot \exp [-\exp (b-c \cdot t)]+e_{i}
$$

em que:

$\mathrm{a}=$ assíntota (massa esperada à maturidade);

$\mathrm{b}$ e c = parâmetros de escala sem significado biológico;

$\mathrm{t}=$ tempo em semanas;

$\mathrm{e}_{\mathrm{i}}=$ erro associado à observação, suposto $\operatorname{NID}\left(0 ; \sigma^{2}\right)$.

Posteriormente, foi empregado um teste para verificar a igualdade de parâmetros e a identidade de modelos de regressão não linear, sendo testadas as hipóteses:

$\mathrm{H}_{0}(1): \mathrm{a}_{1}=\mathrm{a}_{2}=\mathrm{a}_{3}=\mathrm{a}_{4}=\mathrm{a}_{5}=\mathrm{a}$ vs $\mathrm{H}_{\mathrm{a}}(1)$ : nem todos $\mathrm{a}_{\mathrm{i}}$ são iguais;

$H_{0}(2): b_{1}=b_{2}=b_{3}=b_{4}=b_{5}=b$ vs $H_{a}(2):$ nem todos $b_{i}$ são iguais;

$\mathrm{H}_{0}(3): \mathrm{c}_{1}=\mathrm{c}_{2}=\mathrm{c}_{3}=\mathrm{c}_{4}=\mathrm{c}_{5}=\mathrm{c}$ vs $\mathrm{H}_{\mathrm{a}}(3):$ nem todos $\mathrm{c}_{\mathrm{i}}$ são iguais;

$\mathrm{H}_{0}(4): \mathrm{a}_{1}=\mathrm{a}_{2}=\mathrm{a}_{3}=\mathrm{a}_{4}=\mathrm{a}_{5}=\mathrm{a}, \mathrm{b}_{1}=\mathrm{b}_{2}=\mathrm{b}_{3}=\mathrm{b}_{4}=\mathrm{b}_{5}=\mathrm{b}, \mathrm{c}_{1}$ $=\mathrm{c}_{2}=\mathrm{c}_{3}=\mathrm{c}_{4}=\mathrm{c}_{5}=\mathrm{c}$

vs $H_{a}$ (4): pelo menos uma igualdade é uma desigualdade e empregado o teste da razão de verossimilhança entre variâncias, que após linearização por transformação logarítmica segue distribuição Qui-quadrado, conforme Regazzi (2003). Os dados foram analisados utilizando-se o pacote estatístico computacional SAEG (UFV, 1999). O modelo estatístico utilizado foi o seguinte:

$$
\mathrm{Y}_{\mathrm{ij}}=\mu+\mathrm{t}_{\mathrm{i}}+\mathrm{e}_{(\mathrm{i}) \mathrm{j}} \text {; }
$$

em que:

$\mathrm{Y}_{\mathrm{ij}}$ : observação referente ao i-ésimo tratamento sobre a jésima repetição;

$\mu$ : constante geral;

$\mathrm{t}_{\mathrm{i}}$ : efeito relativo ao tratamento i $(\mathrm{i}=1,2,3,4$ e 5$) \mathrm{e}$;

$\mathrm{e}_{(\mathrm{i}) \mathrm{j}}$ : compõe o erro aleatório, associado a cada observação, suposto NID $\left(0 ; \sigma^{2}\right)$.

Para as variáveis ganho em massa corporal acumulado, peso médio das aves e conversão alimentar média foi aplicado o teste de Cochran \& Bartelett para verificar a homocedasticidade de variâncias e, quando necessário, efetuada a transformação logarítmica, de forma a atender a esta pressuposição (NETER \& WASSERMAN, 1974).

A resposta das variáveis analisadas foi avaliada em função da decomposição da soma de quadrados referentes aos níveis de lisina em seus componentes linear, quadrático e cúbico. Os efeitos foram considerados significativos 
quando $\mathrm{P}<0,05$, respeitando-se a interpretação biológica para cada variável e nível significativo.

\section{RESULTADOS E DISCUSSÃO}

As temperaturas médias mínima e máxima verificadas durante o período foram, respectivamente, $20,63 \pm 3,02^{\circ} \mathrm{C}$ e $28,42 \pm 2,98^{\circ} \mathrm{C}$. O ITGU calculado para o período experimental foi de 73,4 $\pm 3,96$. Segundo Medeiros \& Vieira (1994), o ITGU abaixo de 72 é mais propício para criação de animais oriundos de clima temperado, nos trópicos, porém até 76 não há efeito sobre a homeostase.

A mortalidade registrada no período foi de $11 \%$, estando dentro do índice zootécnico aceitável. A uniformidade média não foi afetada pelos tratamentos, sendo calculada em $87,50 \%$. Isso indica que todas as aves conseguiram consumir quantidade homogênea de nutrientes, não caracterizando efeito de dominância entre elas ou problemas de ordem patológica.

Não foi verificado efeito dos níveis de lisina total $(\mathrm{P}>0,05)$ sobre nenhuma das características de desempenho avaliadas no presente estudo, conforme Tabela 2. Os resultados indicam que a lisina contida na ração basal (sem suplementação) foi suficiente para atender às exigências das aves no período de um a 42 dias de vida.

As médias das variáveis são semelhantes às relatadas por Murakami \& Ariki, (1998) e Pinto (2002). Porém, Pinto (2002) constatou que o ganho de peso e a conversão alimentar foram afetados de forma quadrática pela suplementação de lisina na ração. Similarmente às galinhas poedeiras e ao contrário do observado com pintos de corte, a codorna japonesa parece não responder ao aumento dos níveis de lisina na ração.

$\mathrm{Na}$ fase inicial, as aves, são menos eficientes em depositar proteína dietética quando comparadas às aves mais velhas. Isto pode estar associado ao baixo consumo de ração e reduzida eficiência digestiva, o que eleva a taxa de degradação protéica, para compensar a alta demanda energética das aves jovens (KESSLER, 2001). Shin \& Vohra (1984) explicam que as codornas japonesas destinadas à postura apresentam baixa capacidade de deposição tecidual após 35 dias de vida, devido à elevada massa de ovos produzida diariamente.

O nível de proteína bruta de $20,70 \%$ utilizado no presente estudo, abaixo do descrito no NRC (1994), pode ter contribuído para a não-observação de diferença estatística entre os tratamentos. A relação lisina: proteína bruta para o menor nível utilizado, foi de $4,34 \%$, próximo ao valor de $5,4 \%$ descrito no NRC (1994). Isso foi possível mesmo reduzindo o percentual de proteína bruta da ração para $20,70 \%$, contra os o $24,0 \%$ relatados no NRC (1994) e o de lisina total para 0,90\%. Sob a ótica econômica, isso pode favorecer a redução do custo das formulações, devido a uma menor inclusão de ingredientes protéicos, que participam com cerca de $25 \%$ no custo total da ração, conforme constado por Pinto (2002).

Mediante o teste de identidade de modelos, não foram detectadas diferenças entre os perfis de crescimento das codornas que receberam os diferentes níveis de lisina. Portanto, foi ajustada uma única equação para descrever o crescimento exibido pelas codornas que receberam os diferentes tratamentos, conforme se depreende da Tabela 3 e da Figura 1.

Apesar da codorna aumentar a sua massa corporal em aproximadamente 10 vezes nos primeiros 21 dias, esse ganho de massa é reflexo de uma maior síntese de tecido ósseo do que propriamente de hipertrofia muscular.

O resultado de peso vivo obtido no presente estudo $(120,7 \mathrm{~g})$ é inferior ao observado por Barreto et al. (2006), que trabalhando com codornas européias observaram médias de 210,6g de peso vivo aos 49 dias de idade. Esses resultados evidenciam o maior potencial da codorna européia para ganho de peso, uma vez que sua seleção genética é direcionada para esse fim.

TABELA 2 - Desempenho de codornas japonesas aos 42 dias de idade em função do nível de lisina na ração.

\begin{tabular}{lrrrrrrr}
\hline & \multicolumn{9}{c}{ Níveis de lisina na ração $(\%)$} & & \\
\cline { 2 - 6 } Variáveis & $\mathbf{0 , 9 0}$ & $\mathbf{1 , 0 5}$ & $\mathbf{1 , 2 0}$ & $\mathbf{1 , 3 5}$ & $\mathbf{1 , 5 0}$ & Média & CV (\%) \\
\hline Peso médio das aves (g) & $120,5^{*}$ & $121,5^{*}$ & $120,9^{*}$ & $121,1^{*}$ & $119,5^{*}$ & 120,7 & 2,4 \\
Consumo de ração acumulado & $450,2^{*}$ & $457,4^{*}$ & $449,1^{*}$ & $449,5^{*}$ & $447,8^{*}$ & 450,8 & 2,4 \\
(g/ave/período) & $10,72^{*}$ & $10,87^{*}$ & $10,70^{*}$ & $10,70^{*}$ & $10,66^{*}$ & 10,70 & 2,41 \\
Consumo médio de ração (g/ave/dia) & $113,0^{*}$ & $114,1^{*}$ & $113,8^{*}$ & $113,8^{*}$ & $112,1^{*}$ & 113,4 & 2,56 \\
Ganho de massa corporal & $4,60^{*}$ & $4,50^{*}$ & $4,60^{*}$ & $4,48^{*}$ & $4,49^{*}$ & 4,50 & 3,98 \\
acumulado (g) & & & & & &
\end{tabular}

*efeito não-significativo pelo Teste $\mathrm{F}(\mathrm{P}>0,05)$. 
TABELA 3 - Estimativas dos parâmetros da curva de crescimento animal de acordo com modelo de Gompertz (1925).

\begin{tabular}{clcc}
\hline \multirow{2}{*}{ Parâmetros } & \multicolumn{3}{c}{ Limites } \\
\cline { 2 - 4 } & \multicolumn{1}{c}{ Médias } & Inferior & Superior \\
\hline $\mathrm{a}^{1}$ & $143,1 \pm 1,616$ & 139,9 & 146,3 \\
$\mathrm{~b}^{2}$ & $1,2216 \pm 0,016$ & 1,1899 & 1,2532 \\
$\mathrm{c}^{3}$ & $0,0721 \pm 0,0015$ & 0,0692 & 0,0751 \\
\hline
\end{tabular}

${ }^{1}$ Assíntota (massa esperada à maturidade)

2 e 3 parâmetros de escala sem significado biológico.

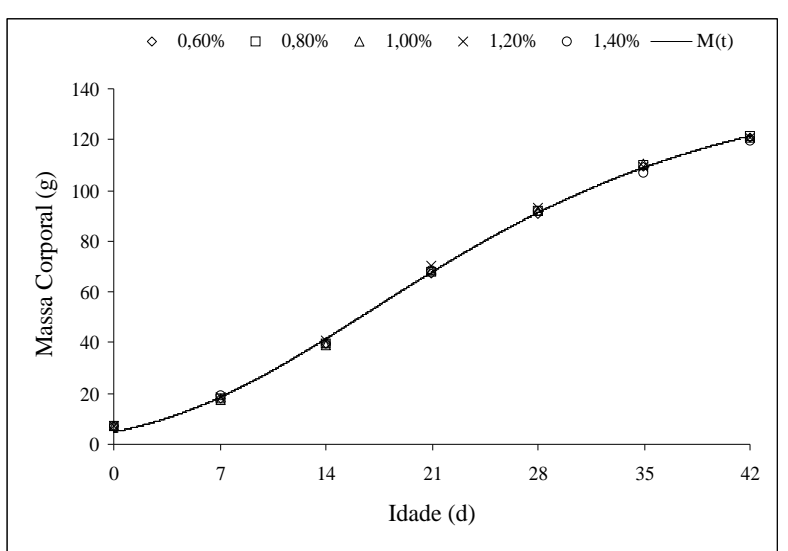

FIGURA 1 - Curva de crescimento de codornas japonesas alimentadas com diferentes níveis de lisina de 1 a 42 dias de idade.

Baseado nos resultados obtidos neste estudo, não há necessidade de suplementação da codorna com lisina sintética quando fornecida ração com nível de $0,90 \%$ de lisina total e $20,7 \%$ de proteína bruta, sendo necessário um consumo diário de $96,6 \mathrm{mg}$ de lisina total por codorna. Assertiva semelhante à de Barreto et al. (2006), que recomendaram o nível de $0,90 \%$ de lisina total em rações com $20,14 \%$ de proteína bruta para codornas européias de 21 aos 49 dias.

\section{CONCLUSÃO}

O nível de $0,90 \%$ de lisina total, em rações com $20,70 \%$ de proteína bruta, atende às exigências para codornas japonesas na fase de cria (1 a 42 dias).

\section{REFERÊNCIAS BIBLIOGRÁFICAS}

BAKER, D. H.; HAN, Y. Ideal amino acid profile for chicks during the first three weeks posthatching. Poultry Science Journal, London, v. 73, n. 9, p. 1441-1447, 1994.
BARRETO, S. L. T.; ARAÚJO, M. S.; UNIGI, R. T. Exigência nutricional de lisina para codornas européias machos de 21 a 49 dias de idade. Revista Brasileira de Zootecnia, Viçosa, v. 35, n. 3, p. 750-753, 2006.

BERTECHINI, A. G.; KATO, R. K.; FASSANI, E. J. Novos conceitos aplicados à produção de codornas. In: SIMPÓSIO INTERNACIONAL DE COTURNICULTURA, 1., 2002, Lavras. Anais... Lavras: UFLA; NECTA, 2002. p. 218.

BUFFINGTON, D. E.; COLAZZO-AROCHO, A.; CANTON, G. H.; PITT, D. Black globe-humitidy index (BGHI) as confort equation for dairy cows. Transaction of the Asae, [S.1.], v. 24, p. 711-714, 1981.

GOMPERTZ, B. On nature of the function expressive of the law of human mortality, and on a new mode of determining the value of life contingencies. Philos. Trans. Research Society, [S.1.], v. 115, p. 513-585, 1825.

KESSLER, A. M. Aminoacid metabolism in young poultry. In: LA WORKSHOP OF POULTRY AND SWINE AJINOMOTO BIOLATINA, 1., 2001, Foz do Iguaçu, PR. Anais... Foz do Iguaçu: Ajinomoto Biolatina, 2001. p. 8698.

KLASING, K. C. Amino acid. In: Comparative avian nutrition. Wallingford, UK: CAB International, 1998. p. 133-170.

MEDEIROS, L. F. D.; VIEIRA, D. Bioclimatologia zootécnica. Seropédica: UFRRJ, 1994. 86 p. Apostila.

MURAKAMI, A. E.; ARIKI, J. Produção de codornas japonesas. Jaboticabal: FUNEP, 1998. 79 p.

NASCIMENTO, A. Lisina: principal aminoácido para deposição protéica. Disponível em: <www.lisina.com.br/ artigos>. Acesso em: 28 jul. 2003.

NATIONAL RESEARCH COUNCIL. Nutrient requirements of poultry. Washington, DC: National Academic, 1994.

NETER, J.; WASSERMAN, W. Applied linear statistical models regression, analysis of variance and experimental designs. Washington, DC: R. D. Irwin, 1974. 473 p. 
PINTO, R. Exigência de metionina mais cistina e de lisina para codornas japonesas nas fases de crescimento e de postura. 2002. 104 f. Tese (Doutorado em Zootecnia) Universidade Federal de Viçosa, Viçosa, 2002.

REGAZZI, A. J. Teste para verificar a igualdade de parâmetros e a identidade de modelos de regressão não linear. Revista Ceres, Viçosa, v. 50, n. 287, p. 9-26, 2003.

ROSTAGNO, H. S.; ALBINO, L. F. T.; DONZELE, J. L. Composição de alimentos e exigências nutricionais de aves e suínos: tabelas brasileiras. 2. ed. Viçosa: UFV, 2000. 141 p.

SHIN, K. F.; VOHRA, P. A. A review of the nutrition of Japanese quail. World's Poultry Science Journal, London, v. 40, n. 3, p. 261-274, 1984.
SILVA, D. J. Análise de alimentos: métodos químicos e biológicos. 2. ed. Viçosa: UFV, 1990. 165 p.

SUIDA, D. Formulação por proteína ideal e conseqüências técnicas, econômicas e ambientais. In: SIMPÓSIO INTERNACIONAL DE NUTRIÇÃO ANIMAL, 1., 2001, Santa Maria. Anais... Santa Maria: CBNA, 2001. p. 1-17.

UNIVERSIDADE FEDERAL DE VIÇOSA. SAEG - Sistema para análise estatística e genética. Versão 8.0. Viçosa: Fundação Arthur Bernardes, 1999.

ZWIETERING, M. H.; JONGENBURGUER, I.; ROMBOUTS, F. M.; RIET, K. V. Modeling of the bacterial growth curve. Applied and Environmental Microbiology, [S.1.], v. 56, n. 6, p. 1875-1881, 1990. 